Michael Maes*, Ana Congio, Juliana Brum Moraes, Kamila Landucci Bonifacio, Decio Sabbatini Barbosa, Heber Odebrecht Vargas, Gerwyn Morris, Basant K. Puri, Ana Paula Michelin, Sandra Odebrecht Vargas Nunes

\title{
Early Life Trauma Predicts Affective Phenomenology and the Effects are Partly Mediated by Staging Coupled with Lowered Lipid- Associated Antioxidant Defences.
}

https://doi.org/10.1515/bmc-2018-0010

received August 28, 2018; accepted November 1, 2018.

\begin{abstract}
Background: Early life trauma (ELT) may drive mood disorder phenomenology, nitro-oxidative pathways and impairments in semantic memory. There are no data regarding the impact of ELT on affective phenomenology and whether these pathways are mediated by staging or lowered lipid-associated antioxidant defences.
\end{abstract}

Methods: This study examined healthy controls $(\mathrm{n}=54)$ and patients with affective disorders including major depression, bipolar disorder and anxiety disorders ( $\mathrm{n}=118)$. ELT was assessed using the Child Trauma Questionnaire. In addition, we measured affective phenomenology and assayed advanced oxidation protein products; malondialdehyde, paraoxonase 1 (CMPAase) activity, high-sensitivity C-reactive protein (hsCRP), and high-density lipoprotein (HDL) cholesterol.

Results: ELT was associated with increased risk for mood and comorbid anxiety disorders and a more severe phenomenology, including staging characteristics,

*Corresponding author: Michael Maes, Health Sciences Graduate Program, Health Sciences Center, State University of Londrina, Av. Robert Koch 60 ; 86035-380, Londrina, PR, Brazil; Department of Psychiatry, Chulalongkorn University, Bangkok, Thailand; Department of Psychiatry, Medical University of Plovdiv, Plovdiv, Bulgaria; IMPACT Strategic Research Centre, Deakin University, Geelong, Vic, Australia, E-mail: dr.michaelmaes@hotmail.com Ana Congio, Juliana Brum Moraes, Kamila Landucci Bonifacio, Decio Sabbatini Barbosa, Heber Odebrecht Vargas, Ana Paula Michelin, Sandra Odebrecht Vargas Nunes: Health Sciences Graduate Program, Health Sciences Center, State University of Londrina, Av. Robert Koch 60 ; 86035-380, Londrina, PR, Brazil

Gerwyn Morris: IMPACT Strategic Research Centre, Deakin University, Geelong, Vic, Australia

Basant K. Puri: Department of Medicine, Imperial College London, London, UK depression and anxiety severity, suicidal behaviours, type of treatments, disabilities, body mass index, smoking behaviour and hsCRP, as well as lowered health-related quality of life, antioxidant defences and semantic memory. The number of mood episodes and CMPAase/HDLcholesterol levels could be reliably combined into a new vulnerability staging-biomarker index, which mediates in part the effects of ELT on affective phenomenology and oxidative stress. Moreover, the effects of female sex on mood disorders and affective phenomenology are mediated by ELT.

Discussion: The cumulative effects of different ELT drive many aspects of affective phenomenology either directly or indirectly through effects of staging and/or lipid-associated antioxidant defences. The results show that children, especially girls, with ELT are at great risk to develop mood disorders and more severe phenotypes of affective disorders.

Keywords: depression; bipolar disorder; immune; inflammation; oxidative; nitrosative stress.

\section{Introduction}

Both major depressive disorder (MDD) and bipolar disorder (BD) are highly recurrent disorders that are characterized by increased risk for suicidal behaviours [1-3], lowered health-related quality of life (HR-QoL), increased disabilities [4-7], lowered socio-economic status [8-11], smoking behaviours [12-14], increased incidence of metabolic syndrome [15] and cognitive impairments including semantic memory deficits [16].

There is also evidence that neuro-immune, neurooxidative and neuro-nitrosative pathways play a key 
role in the pathophysiology of both MDD and BD [17-20]. Both mood disorders are associated with lowered lipidassociated antioxidant defences, which protect against the detrimental effects of reactive oxygen species (ROS), including lowered lecithin cholesterol acyltransferase (LCAT) and paraoxonase (PON1) activities and lowered high-density lipoprotein (HDL)-cholesterol, vitamin $\mathrm{E}$ and coenzyme $\mathrm{Q}_{10}$ levels [21-30]. These lowered lipid-associated antioxidant defences contribute to increased ROS production and consequent damage to lipid membranes, including omega-3 long-chain polyunsaturated fatty acids [30-33] and proteins [34,35]. Such reactions may lead to the production of advanced oxidation protein products (AOPP) [34,35], generation of neoepitopes including malondialdehyde (MDA) and azelaic acid, and IgM-mediated autoimmune responses directed against those neoepitopes [20,30,36-41]. Lowered PON1 (CMPAase) activity is tightly coupled with lowered HDL-cholesterol levels and number of depressive and (hypo)manic episodes [29]. Importantly, in the plasma PON1 is bound to HDL molecules thereby protecting HDL against oxidation [29]. Activated immune-inflammatory pathways, which are tightly connected with enhanced oxidative stress pathways, are other hallmarks of mood disorders [20], and include increased levels of proinflammatory cytokines and acute phase proteins, such as C-reactive protein (CRP) [17,42]. The activated neuroimmune and neuro-oxidative pathways in mood disorders may attenuate the PON1 - HDL binding and damage both PON1 and HDL functions [29]. Nevertheless, the sources of these activated oxidative and immune pathways are not completely elucidated, although leaky gut, leaky teeth and psychological stressors are involved [34,43,44].

Early life trauma (ELT), including physical and emotional neglect or abuse and sexual abuse as well as parental discord and bullying, is an environmental factor associated with the onset of affective disorders [45-52]. ELTs impact the course of illness and may cause more recurrent episodes [53,54], increase severity of illness and suicidal behaviours $[51,55,56]$, increase comorbid anxiety disorders [57,58] and obesity [59] and delay neurocognitive development [60]. Women show a higher incidence of affective disorders and higher scores on severity of illness as compared with men [61-63], whilst women also report more ELTs than men [64]. Nevertheless, it has remained elusive whether the effects of female sex on affective phenomenology are mediated by ELTs, and whether the effects on affective phenomenology are mediated by staging characteristics.

There is also evidence that ELTs may sensitize and activate neuro-immune and neuro-oxidative pathways. For example, in mood disorders, physical neglect was significantly associated with indicants of lipid peroxidation, nitro-oxidative stress and lipid and protein oxidation, while sexual abuse was accompanied by lowered antioxidant levels including zinc, albumin and SH groups [65]. ELTs are positively associated with increased pro-inflammatory cytokines and CRP, while these aberrations may persist in euthymic phases of $\mathrm{BD}$ [review: 66]. In another study, increased levels of hsCRP were significantly associated with sexual abuse rather than with BD, whilst the differences in hsCRP between BD patients and controls disappeared after controlling for body mass index (BMI) [66].

Hence, the aim of this study was to examine whether ELTs are associated with mood disorders, comorbid anxiety, staging characteristics (number of mood episodes and lifetime suicidal attempts), current suicidal ideation, severity of illness, type of treatments, increased disabilities and lowered HR-QoL, socio-economic variables (income and education), BMI, smoking behaviour, semantic impairments, lipid-associated antioxidant defences (HDLcholesterol and PON1 activity), lipid/protein oxidation and hsCRP. Secondly we examine whether the effects of female sex on affective phenomenology are mediated by ELTs and whether the effects of ELTs on affective phenomenology are mediated by staging characteristics or biomarkers.

\section{Methods}

\section{Study population}

This study examined ELT in 54 controls and 118 participants with affective disorders recruited at the outpatient Psychiatric Clinics at the University Hospital of the Universidade Estadual de Londrina (UEL), Parana, Brazil. We included participants aged 18 to 65 years, either sex, and from all ethnicities (self-declared). The controls were recruited by word of mouth from the same catchment area as the patients, namely Parana, Brazil. We included patients with MDD $(n=37), B D(n=68)$ and DSM-IV-TR anxiety disorders ( $\mathrm{n}=81$, namely generalized anxiety disorder (GAD), social phobia, simple phobia and panic disorder). Patients with mood disorders were in (partial) remission and the index episode was not of (hypo)manic polarity. All participants provided written informed consent to take part in the study, with the experimental procedures being approved by the Research Ethics Committee at UEL (protocol number: CAAE 34935814.2.0000.5231). 
We excluded the following participants: pregnant women, participants with mental disorders other than BD, MDD or anxiety disorders, including schizophrenia, psycho-organic disorders, neuro-inflammatory and neurodegenerative disorders, including multiple sclerosis, Parkinson and Alzheimer's disease, participants who were taking omega-3 polyunsaturated fatty acids or antioxidant agents during the past four weeks prior to inclusion in the study, and subjects who had ever taken non-steroidal anti-inflammatory drugs, interferon or glucocorticoids. Furthermore, we excluded subjects with medical conditions that are characterized by immune activation or immunosuppression, such as hepatitis B and $\mathrm{C}$ virus infection, HIV infection, acute and chronic renal failure, inflammatory bowel disease, chronic obstructive pulmonary disease, rheumatoid arthritis and type I diabetes.

\section{Clinical assessments}

Patients and controls completed a semi-structured interview, which comprised socio-demographic data, education (in years), employment status, income (in reais/ month) and marital status. The interview also included (a) the number of depressive and manic episodes, and total number of episodes; and (b) the use of medication, including antidepressants, antipsychotics, lithium and anticonvulsant stabilizers.

ELT was assessed using the Childhood Trauma Questionnaire (CTQ). This is a self-rating scale for adolescents and adults investigating a history of physical and emotional abuse or neglect and sexual abuse during childhood; the frequency of each ELT is rated on a fivepoint Likert scale applied to 28 items [67,68]. We used a Portuguese version of the CTQ instrument validated for use in the Brazilian population [68].

Diagnoses of MDD, BD, and anxiety disorders were made by trained research psychiatrists using the Structured Clinical Interview for the DSM-IV-TR (clinical version) translated and validated for application in Brazilian samples [69]. Severity of depression was assessed employing the 17-item Hamilton Depression Rating Scale (HAMD) [70], translated and validated for the Brazilian population [71]. Severity of anxiety was assessed employing the Hamilton Anxiety Rating Scale (HAMA) [72]. We used the Columbia-Suicide Severity Rating Scale (C-SSRS) to rate severity of current suicidal ideation and number of prior suicide attempts and used a validated Portuguese translation [73,74].
The Clinical Global Impressions (CGI) scale was used to assess overall severity of illness, which scores the subject status on a scale from 1 to 7 [75]. We used the Sheehan Disability Scale to assess disabilities. This self-rating scale scores occupational, social life, leisure, family life, activities, and household activities [76]. The WHO Quality of Life Instrument-Abbreviated Version (WHO-QOLBREF) [77] was used in a validated Brazilian Portuguese translation [78]. We used the sum of the four WHO-QoL domains, namely physical health, psychological health, social relationships and environment. A subset of the participants $(n=83)$ also completed the Verbal Fluency Test (VFT), animal category. We used DSM-IV-TR criteria to make the diagnosis of tobacco use disorder (TUD). Body mass index (BMI) was calculated as body mass (kg) divided by square of height $\left(\mathrm{m}^{2}\right)$.

\section{Biomarker measurements}

Peripheral blood was sampled at 8 a.m. after $12 \mathrm{~h}$ fasting, on the same day as the semi-structured interview and clinical ratings. We assessed the levels of hsCRP, MDA, AOPP, PON1 activity, and HDL-cholesterol. MDA levels were assessed using both the thiobarbituric acid (TBA) assay, in which MDA reacts with TBA to generate the colored (TBA) $)_{2}$ MDA adduct, and by high-performance liquid chromatography (HPLC; Alliance e2695, Waters', Barueri, SP, Brasil) [79]. Experimental conditions included the use of a column Eclipse XDB-C18 (Agilent, USA); mobile phase consisting of $65 \%$ phosphate buffer (50 nM pH 7.0) and 35\% HPLC-grade methanol; flow rate of $1.0 \mathrm{~mL} /$ minute; temperature of $30{ }^{\circ} \mathrm{C}$; wavelength of $532 \mathrm{~nm}$ (the absorption frequency of (TBA) - MDA). MDA concentration in the samples was quantified based on a calibration curve and was expressed in $\mu \mathrm{mol} \mathrm{MDA} / \mathrm{mg}$ proteins. AOPP was quantified spectrophotometrically using the method described by Hanasand et al. [80] using a microplate reader, model EnSpire (Perkin Elmer, Waltham, MA, EUA) with an absorbance wavelength of $340 \mathrm{~nm}$. AOPP concentration was expressed in chloramine units $(\mu \mathrm{M})$. PON1 activity was determined using 4-(chloromethyl)phenyl acetate (CMPA; Sigma, USA), which is an alternative to the use of the toxic paraoxon [29]. The analysis was conducted in a spectrophotometer microplate reader (EnSpire, Perkin Elmer, USA). All assays were carried out in triplicate and replicates that varied by $10 \%$ or greater were repeated. The CMPAase activity levels were adjusted for PON1 genotypes using regression analysis. HDL-cholesterol was assayed by automated methods using the Dimension RxL (Deerfield, IL, USA). 
hsCRP was assayed using a nephelometric assay (Behring Nephelometer II, Dade Behring, Marburg, Germany). The inter-assay coefficients of variability were less than $10 \%$.

\section{Statistics}

Analysis of variance(ANOVA) was used to assess differences in scale variables (e.g. clinical, socio-demographic and biomarker data) between categories, while analysis of contingency tables ( $\chi^{2}$-test) was used to check associations between nominal variables. Binary logistic regression analysis was used to check the significant explanatory variables predicting binary outcome variables, including $\mathrm{BD}$ (versus no $\mathrm{BD}$ ), any anxiety disorders (versus no anxiety disorder) and TUD (with no-TUD as a reference group). All tests were two-tailed and an alpha level of 0.05 was considered to be statistically significant. All analyses were performed using the IMB-SPSS software version 24 for Windows. We used SmartPLS (Partial Least Squares) analysis, a structural equation modeling technique coupled with path modeling using PLS-structural equation modeling algorithms [81] to examine the effects of ELTs (input variable) on affective phenomenology (output variables). Variables were included as single indicators (e.g. BMI, income) or as latent vectors (LV) extracted from indicator variables in reflective models (e.g. the four WHO-QoL domain scores reflecting general HR-QoL). PLS path analysis was only performed when the model and constructs complied with specific quality criteria, namely: (a) model fit standardized root mean residual (SRMR) < 0.08 [81]; (b) composite constructs have good discriminant validity and reliability as indicated by average variance extracted (AVE) > 0.5; Cronbach's alpha > 0.7, composite reliability > 0.7 and rho_A $>0.8$; (c) indicators are only included in LVs when the factor loadings are $>0.45$ with $\mathrm{p}<0.01$; (d) construct cross-validated redundancies and communalities are checked [82]. Consequently, consistent PLS bootstrapping (2000 bootstraps) was used to compute path coefficients with $\mathrm{t}$-values and exact $\mathrm{p}$-values, total effects, total indirect and specific indirect effects and $\mathrm{t}$-values for the outer model.

\section{Results}

\section{Construction of an ELT LV and staging LV}

In order to examine whether a first LV extracted from the five ELT data (ELT-LV) performed well as a composite score we used PLS factor analysis and calculated composite reliability data. The LV extracted from the 5 ELT data shows that ELT-LV has an adequate Cronbach alpha (0.848), composite reliability (0.893) and rho_A values (0.877), while the AVE value was very good (0.630). All 5 items scored highly on this LV (all $>0.587$ ). In order to examine whether staging and lipidassociated antioxidant defences (HDL-cholesterol and PON1/residualized CMPAase activity) could be reliably combined in one underlying construct we carried out PLS factor analysis. This showed that the LV extracted from number of depressive episodes, number of hypomanias, CMPAase and HDL-cholesterol showed a good composite reliability (0.808), Cronbach alpha (0.734), rho_A (0.860) and AVE (0.534), while all four variables loaded significantly ( $>0.484)$ on this LV and were significant at the $\mathrm{p}<0.01$ level. This LV was named "EPIBIOL-LV" (from episodes coupled with biomarkers).

\section{Characteristics of the ELT-LV subgroups}

In order to show the measurements of the clinical and biological data in ELT-LV subgroups, we divided the participants into three equal-sized groups based on 33.3333 and 66.6666 percentiles of the ELT-LV scores. Table $1 \mathrm{~s}$ hows the ELT differences between the three groups. Sexual and physical abuse were significantly increased in the high ELT-LV group as compared with the low and medium ELT-LV groups. Scores on emotional abuse and emotional and physical neglect were significantly different between the three groups and increased from the low $\rightarrow$ medium $\rightarrow$ high ELT-LV groups.

Table 2 shows the clinical characteristics of the ELT-LV groups. There were no significant differences in age, marital status, TUD, and BMI between the study groups. The high ELT-LV group was characterized by a higher female-to-male ratio, more lifetime suicide attempts, and current suicidal ideation as compared with the other two groups. The high ELT-LV group was characterized by lower education and income as compared with the low ELT-LV group. Subjects with medium + high ELT-LV scores showed a higher rate of unemployment, more manic episodes, a higher incidence of $\mathrm{BD}$ and a higher HAMA score as compared with subjects with a low ELT-LV score. The HAM-D, CGI, Sheehan and HR-QoL scores were significantly different between the three ELT-LV groups and increased from the low $\rightarrow$ medium $\rightarrow$ high ELT-LV group, while HR-QOL significantly decreased along these groups. 
Table 1: Measurements of five early life trauma (ELT) in subjects divided into high, medium and low values of ELT-latent vector (LV) scores.

\begin{tabular}{|c|c|c|c|c|c|c|}
\hline Variables & $\begin{array}{l}\text { ELT-LV }< \\
-0.6693^{A}\end{array}$ & $\begin{array}{l}-0.6693<\text { ELT-LV } \\
<+0.2217^{\text {B }}\end{array}$ & $\begin{array}{l}\text { ELT-LV } \\
\$+0.2217 \mathrm{c}\end{array}$ & $F / X^{2}$ & df & $\mathbf{p}$ \\
\hline Sexual abuse & $5.09(0.43)^{c}$ & $5.62(1.57)^{c}$ & $8.70(5.21)^{A, B}$ & 22.02 & $2 / 169$ & $<0.001$ \\
\hline Physical abuse & $5.75(1.06)^{c}$ & $7.05(2.37)^{c}$ & $13.02(4.32)^{\mathrm{A}, \mathrm{B}}$ & 101.33 & $2 / 169$ & $<0.001$ \\
\hline Emotional abuse & $5.63(0.92)^{B, C}$ & $9.00(2.76)^{A, C}$ & $16.56(4.51)^{A, B}$ & 186.48 & $2 / 169$ & $<0.001$ \\
\hline Emotional neglect & $6.30(1.65)^{B, C}$ & $9.88(3.94)^{A, C}$ & $17.39(4.18)^{A, B}$ & 153.35 & $2 / 168$ & $<0.001$ \\
\hline Physical neglect & $5.63(1.19)^{B, C}$ & $7.47(2.53)^{A, C}$ & $11.40(3.77)^{A, B}$ & 67.74 & $2 / 169$ & $<0.001$ \\
\hline
\end{tabular}

All results are shown as mean ("SD)

$A, B, C$ : denote pair-wise differences between the three groups

Table 2: Socio-demographic and clinical data of subjects divided into high, medium and low values of an early life trauma (ELT)-latent vector (LV).

\begin{tabular}{|c|c|c|c|c|c|c|}
\hline Variables & $\begin{array}{l}\text { ELT-LV < } \\
-0.6693^{\text {A }}\end{array}$ & $\begin{array}{l}-0.6693<\text { ELT- } \\
\text { LV }<+0.2217^{\text {B }}\end{array}$ & $\begin{array}{l}\text { ELT-LV } \\
\$+0.2217^{c}\end{array}$ & $F / X^{2}$ & df & $\mathbf{p}$ \\
\hline Age (years) & $41.8(11.2)$ & $44.4(11.8)$ & $42.2(10.3)$ & 0.89 & $2 / 169$ & 0.414 \\
\hline Sex (female / male) & $37 / 20^{c}$ & $41 / 17^{c}$ & $51 / 6^{\mathrm{A}, \mathrm{B}}$ & 10.04 & 2 & 0.007 \\
\hline Education (years) & $12.4(6.1)^{c}$ & $11.3(5.0)$ & $9.8(4.1)^{A}$ & 3.56 & $2 / 168$ & 0.031 \\
\hline Income (reais/month) & $3.8(1.5)^{\mathrm{C}}$ & $3.3(1.4)$ & $2.9(1.4)^{A}$ & 4.92 & $2 / 167$ & 0.008 \\
\hline Employed (No/yes) & $14 / 42^{\mathrm{B}, \mathrm{C}}$ & $27 / 31^{A}$ & $32 / 25^{A}$ & 11.73 & 2 & 0.003 \\
\hline Single/Married/separated-widowed & $18 / 29 / 10$ & $13 / 34$ / 11 & 7 / 34 / 16 & 7.01 & 4 & 0.136 \\
\hline Number depressions & $1.48(3.98)^{c}$ & $2.63(3.35)^{c}$ & $5.64(4.79))^{A, B}$ & 15.06 & $2 / 160$ & $<0.001$ \\
\hline Number (hypo)mania & $0.47(1.64)^{B, C}$ & $3.43(5.75)^{A}$ & $4.12(6.45)^{A}$ & 8.30 & $2 / 169$ & $<0.001$ \\
\hline HAMD & $4.0(5.8)^{B, C}$ & $6.7(7.9)^{A, C}$ & $10.7(6.3)^{A, B}$ & 18.00 & $2 / 169$ & $<0.001$ \\
\hline HAMA & $7.0(7.9)^{\mathrm{B}, \mathrm{C}}$ & $11.5(9.8)^{A}$ & $17.1(9.7)^{\mathrm{A}}$ & 16.15 & $2 / 158$ & $<0.001$ \\
\hline Number suicide attempts & $0.65(3.15)^{c}$ & $0.52(1.35)^{c}$ & $2.18(3.74)^{A, B}$ & 5.68 & $2 / 169$ & 0.004 \\
\hline Current suicidal ideation (No/Yes) & $50 / 7^{c}$ & $56 / 2^{c}$ & $36 / 21^{A, B}$ & 23.84 & 2 & $<0.001$ \\
\hline No mood disorder / BD / MDD & $39 / 7 / 11^{\mathrm{B}, \mathrm{C}}$ & $19 / 26 / 13^{A}$ & $9 / 35 / 13^{A}$ & 39.34 & 4 & $<0.001$ \\
\hline No anxiety / Anxiety disorders & $42 / 15^{c}$ & $31 / 27$ & $18 / 39^{A}$ & 20.29 & 2 & $<0.001$ \\
\hline CGI & $2.36(1.63)^{B, C}$ & $3.30(1.36)^{A, C}$ & $3.95(1.17)^{A, B}$ & 18.41 & $2 / 166$ & $<0.001$ \\
\hline Total Sheehan score & $5.3(8.4)^{B, C}$ & $11.2(9.5)^{A, C}$ & $15.7(9.8)^{A, B}$ & 18.02 & $2 / 168$ & $<0.001$ \\
\hline Total Who-Qol score & $93.1(13.1)^{B, C}$ & $84.8(15.0)^{A, C}$ & $71.4(14.7)^{A, B}$ & 33.51 & $2 / 168$ & $<0.001$ \\
\hline No TUD / TUD & $31 / 26$ & $25 / 33$ & $21 / 36$ & 3.65 & 2 & 0.162 \\
\hline Body mass index $\left(\mathrm{kg} / \mathrm{m}^{2}\right)$ & $25.7(4.9)$ & $26.2(4.4)$ & $27.6(5.2)$ & 2.31 & $1 / 161$ & 0.103 \\
\hline
\end{tabular}

All results are shown as mean (“SD)

$A, B, C$ : denote pair-wise differences between the three groups

HAMD: Hamilton Depression Rating Scale; HAMA: Hamilton Anxiety Rating Scale; BD: bipolar disorder; MDD: major depressive disorder; CGI: clinical global impression; WHO-QoL: WHO-Quality of Life; TUD: tobacco use disorder.

Table 3 shows the measurements of the biomarkers and VFT results in the three ELT-LV groups. The EPIBIOL-LV was significantly different between the three groups and increased from the low to high ELT groups. Verbal fluency was significantly lower in the high ELT-LV group as compared with the low ELT-LV group.

\section{Effects of ELT-LV and EPIBIOL-LV on affective phenomenology}

Consequently, we constructed a PLS path model as shown in Figure $\mathbf{1}$ with affective phenomenology as outcome variables (diagnosis, disabilities, HR-QoL, CGI, severity, suicidal attempts) and ELT-LV and EPIBIOLLV as explanatory variables, while sex was also an 
Table 3: Biomarker data and verbal fluency test (VFT) results in subjects divided into high, medium and low values of an early life trauma (ELT) latent vector (LV).

\begin{tabular}{|c|c|c|c|c|c|c|}
\hline Variables & $\begin{array}{l}\text { ELTFA-HOC }< \\
-0.6693^{A}\end{array}$ & $\begin{array}{l}-0.6693<\text { ELTFA- } \\
\text { HOC }<+0.2217^{\text {в }}\end{array}$ & $\begin{array}{l}\text { ELTFA-HOC } \\
\$+0.2217^{c}\end{array}$ & $\mathbf{F}$ & df & $\mathrm{p}$ \\
\hline HDL-cholesterol (mg/dL) & $51.0(17.0)$ & $48.0(15.7)$ & $46.2(12.8)$ & 1.32 & $2 / 156$ & 0.270 \\
\hline Residualized CMPAase (z scores) & $0.25(0.96)$ & $-0.12(1.03)$ & $-0.13(0.98)$ & 2.40 & $2 / 147$ & 0.095 \\
\hline MDA (mmol/mg of protein)* & $63.0(20.1)$ & $67.2(24.2)$ & $64.0(21.7)$ & 0.42 & $2 / 146$ & 0.656 \\
\hline $\operatorname{AOPP}(\mu M)^{\star}$ & $73.2(46.2)$ & $85.9(50.5)$ & $83.9(45.2)$ & 1.05 & $2 / 147$ & 0.353 \\
\hline $\mathrm{hsCRP}(\mathrm{mg} / \mathrm{dL})^{\star}$ & $3.0(3.0)$ & $4.8(7.5)$ & $4.2(4.5)$ & 1.11 & $2 / 157$ & 0.332 \\
\hline EPIBIOL-LV & $-0.48(0.81)^{\mathrm{B}, \mathrm{C}}$ & $+0.01(0.83)^{A, C}$ & $+0.49(1.12)^{A, B}$ & 15.46 & $2 / 168$ & $<0.001$ \\
\hline VFT words / minute & $16.5(5.3)^{c}$ & $13.2(3.6)$ & $13.1(3.6)^{A}$ & 4.06 & $2 / 80$ & 0.021 \\
\hline
\end{tabular}

All results are shown as mean ("SD)

$A, B, C$ : denote pair-wise differences between the three groups

HDL: high density lipoprotein cholesterol; residualized CMPAAse: Paraoxonase 1 levels adjusted for PON1 genotypes; MDA:

malondialdehyde; AOPP: advanced oxidation protein products; hSCRP: high sensitivity C-reactive protein, EPIBIOL-LV: latent vector extracted from biomarkers and number of episodes

explanatory variable for ELT-LV and EPIBIOL-LV and the latter for ELT-LV. The five Sheehan subdomain scores were used as indicators for the "disabilities LV" (the loading of Sheehan 4 subdomain was not significant and thus deleted from the analysis), the four WHO-QoL subdomain scores were employed as indicators for the WHO-QoL LV, HAMA and HAMD as indicators for severity of illness and mood disorders versus controls, any anxiety disorder and $\mathrm{BD}$ as indicators for a "diagnosis LV". Figure 1 shows the outcome of this PLS path model with path coefficients (pc) and exact $\mathrm{p}$-values. The model quality data were excellent with model fit SRMR $=0.064$, composite reliabilities $>0.8$, Cronbach alpha $>0.7$, AVE values $>0.5$ and rho_A values $>0.8$. We found that a large part of the variances in CGI (22.5\%), WHO-QOL (50.0\%), disabilities (32.2\%), severity LV (32.1\%), income (11.8\%) and diagnosis (62.7\%) was explained by effects of EPIBIOL-LV and ELT-LV combined. All these associations remained significant after considering possible intervening effects of BMI and TUD (entered as additional input variables). EPIBIOL-LV had always a greater impact on these outcome variables than the "BIOL-LV" (extracted from the two HDL-cholesterol and PON1 indicators) or "episodes LV" (number of episodes) alone. For example, the impact of EPIBIOL-LV ( $p c=0.317, p<0.001$, see Figure 1) on "disabilities LV" was greater than the impact of BIOL-LV $(\mathrm{pc}=-0.284, \mathrm{p}<0.001)$ or episodes LV ( $p c=-0.220, p=0.007$ ) alone. Lifetime suicidal attempts $(24.7 \%)$ and current suicidal ideation $(12.7 \%)$ were associated with EPIBIOL-LV, although number of episodes, and not antioxidant levels, were the significant predictors. There was a significant effect of ELT-LV, but not EPIBIOL-LV, on BMI. There were specific indirect effects of ELT-LV on CGI $(t=2.99, p=0.003)$, disabilities $(\mathrm{t}=3.36, \mathrm{p}=0.001)$, WHO-Qol $(\mathrm{t}=-4.62, \mathrm{p}<$ $0.001)$, severity $(\mathrm{t}=3.32, \mathrm{p}=0.001)$, suicidal ideation $(\mathrm{t}$ $=3.51, \mathrm{p}<0.001)$, suicide attempts $(\mathrm{t}=4.40, \mathrm{p}<0.001)$, income $(\mathrm{t}=-2.12, \mathrm{p}=0.034)$ and diagnosis $(\mathrm{t}=4.32, \mathrm{p}<$ 0.001). There were highly significant total effects of ELTLV on EPIBIOL-LV $(t=5.70, p<0.001)$ and on all variables shown in Figure 1.

The BIOL-LV was significantly associated with income ( $p c=0.179, p=0.017)$, severity LV $(p c=-0.288, p<0.001)$, CGI (pc $=-0.307, \mathrm{p}<0.001)$, disabilities LV ( $\mathrm{pc}=-0.284$, $\mathrm{p}$ $<0.001)$, WHO-QoL LV ( $\mathrm{pc}=0.277, \mathrm{p}<0.001)$, diagnosis LV ( $p c=-0.236, p<0.001$ ) and an "oxidation LV" with AOPP and MDA as indicator variables ( $\mathrm{pc}=-0.235, \mathrm{p}<0.001$ ). All those effects remained significant after controlling for effects of TUD. There were no associations between this BIOL-LV and BMI, suicidal ideation, suicidal attempts, and use of lithium, antidepressants, mood stabilizers, and antipsychotics.

Binary logistic regression analysis showed that ELT-LV was significantly associated with mood disorders $(\mathrm{W}=22.21, \mathrm{df}=1, \mathrm{p}<0.001, \mathrm{OR}=3.15,95 \% \mathrm{CI}: 1.96-5.09)$; $\mathrm{BD}(\mathrm{W}=21.41, \mathrm{df}=1, \mathrm{p}<0.001, \mathrm{OR}=2.35,95 \% \mathrm{CI}: 1.64-$ 3.37); any anxiety disorder $(\mathrm{W}=15.65, \mathrm{df}=1, \mathrm{p}<0.001$, $\mathrm{OR}=2.03,95 \% \mathrm{CI}: 1.43-2.88)$; employment $(\mathrm{W}=9.81, \mathrm{df}=$ $1, \mathrm{p}=0.002, \mathrm{OR}=0.60,95 \% \mathrm{CI}: 0.43-0.82)$; use of mood stabilizers $(\mathrm{W}=15.48, \mathrm{df}=1, \mathrm{p}<0.001, \mathrm{OR}=2.14,95 \% \mathrm{CI}$ : 1.47-3.13); use of antipsychotics ( $\mathrm{W}=9.35, \mathrm{df}=1, \mathrm{p}=0.002$, $\mathrm{OR}=1.77,95 \% \mathrm{CI}: 1.23-2.54)$ and lithium $(\mathrm{W}=11.83, \mathrm{df}=1, \mathrm{p}$ $=0.001, \mathrm{OR}=2.00,95 \% \mathrm{CI}: 1.35-2.96$ ), but not TUD and use of antidepressants. 


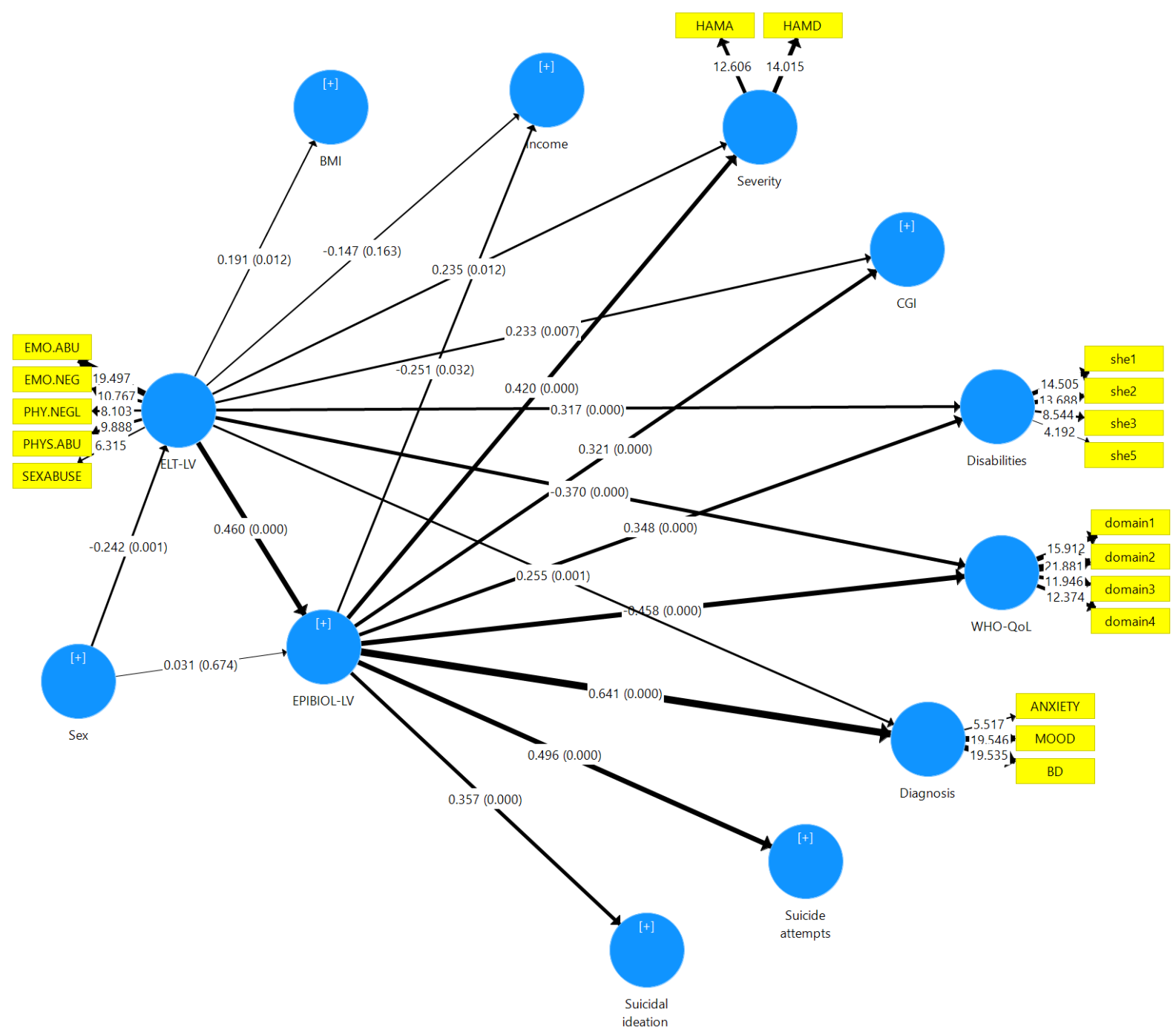

Figure 1: Results of partial least squares path analysis with different aspects of affective phenomenology as outcome variables and latent vectors (LV) extracted from 5 early lifetime trauma (ELT-LV) and number of episodes coupled with lowered lipid-associated antioxidant defences (EPIBIOL-LV) as explanatory variables. Sex was introduced as an explanatory variable for ELT-LV and EPIBIOL-LV. BMI: body masS index, CGI: clinical global impression; disabilities: LV extracted from 4 Sheehan subdomains; WHO-QoL: LV extracted from 4 subdomains; diagnosis: LV extracted from any anxiety disorder, any mood disorder and bipolar disorder.

\section{Effects of sex on affective phenomenology are mediated by ELT-LV}

Table 2shows that there is a significant association between sex and the ELT-LV groups, with significantly more women in the high ELT-LV group. Therefore, we examined the specific indirect effects of sex on affective phenomenology mediated by ELT-LV and sex was added as a direct input variable for ELT-LV and EPIBIOL-LV in the PLS analysis shown in Figure 1. Effect ELT-LV, but not on the EPIBIOLLV. We found significant total effects of sex (male $=1$, female $=0)$ on ELT-LV $(t=-3.45, p=0.001)$, EPIBIOL-LV $(t=$ $-2.76, \mathrm{p}=0.006)$, severityofillness $(\mathrm{t}=-2.61, \mathrm{p}=0.009)$, suicidal ideation $(t=-2.26, p=0.024)$, suicide attempts $(t=-2.52$, $\mathrm{p}=0.012)$, CGI $(\mathrm{t}=-2.80, \mathrm{p}=0.005)$, disabilities $(\mathrm{t}=-2.84, \mathrm{p}$
$=0.005)$, WHO-QoL score $(\mathrm{t}=3.00, \mathrm{p}=0.003)$, income $(\mathrm{t}=$ $2.18, \mathrm{p}=0.030)$, diagnosis $\mathrm{LV}(\mathrm{t}=-3.20, \mathrm{p}=0.001)$ and BMI $(\mathrm{t}=-1.98, \mathrm{p}=0.048)$. All these sex effects were mediated by ELT-LV and/or the path from ELT-LV to EPIBIOL-LV.

\section{Effects of ELT-LV on biomarkers}

We examined whether hsCRP, AOPP or MDA could be combined with the staging data in a reliable LV (as with PON1 activity and HDL-cholesterol in Table 1). These three biomarkers could not be combined with the "episodes LV" to make reliable composite scores. We also examined whether these three biomarkers had comparable effects as EPIBIOL-LV on the clinical outcome data and detected 


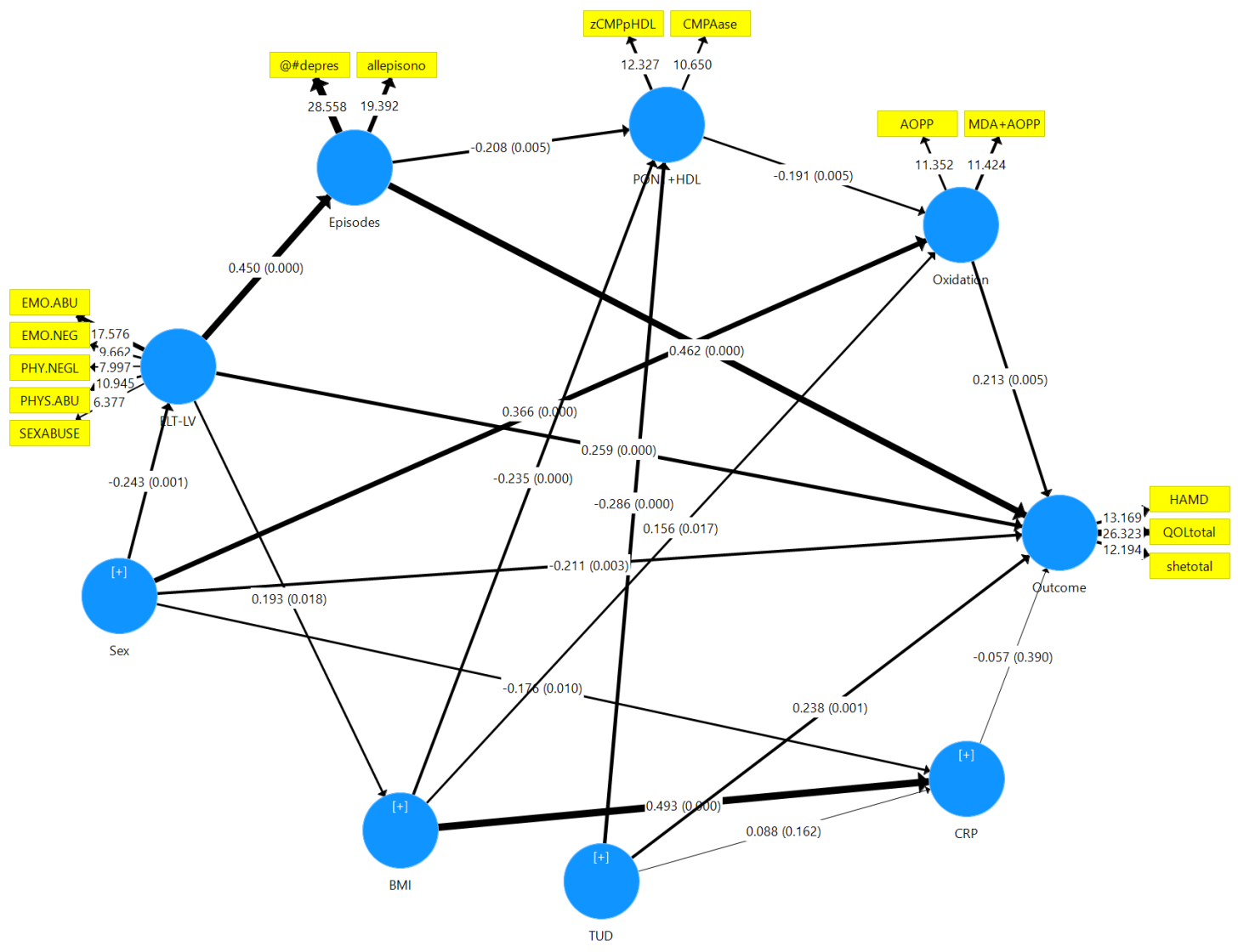

Figure 2: Results of partial least squares (PLS) path model analysis with a latent vector (LV) extracted from the Hamilton Depression rating Scale (HAM-D) score, and the total Sheehan and WHO-QoL scores as an "outcome LV" with as explanatory variables: an oxidation LV, extracted from serum AOPP (advanced oxidation protein products) and MDA (malondialdehyde) levels; LV extracted from HDL (high density lipoprotein cholesterol) and CMPAase (paraoxonase 1 activity) (PON-HDL LV); an episodes LV, extracted from number of depressions and total number of episodes; high sensitive C-reactive protein (hsCRP); body mass index (BMI) and sex. Tobacco use disorder (TUD) was used as explanatory variable for outcome LV, high-sensitive C-reactive protein (hSCRP), oxidation LV (not significant) and the PON-HDL LV.

that only AOPP had some effects, namely on CGI $(\mathrm{t}=4.53$, $\mathrm{p}<0.001)$, WHO-QoL $(\mathrm{t}=-2.56, \mathrm{p}=0.011)$ and severity of illness $(\mathrm{t}=2.55, \mathrm{p}=0.011)$.

In order to examine the effects of ELT-LV on the biomarkers we performed a further PLS path analysis as shown in Figure 2, with HAMD, total Sheehan and total HR-QoL scores as indicators of an "outcome LV" and AOPP/MDA LV, HDL/CMPAase LV, episodes LV, hsCRP and ELT-LV as explanatory variables, while adjusting for TUD, BMI and sex, whereby sex was also an explanatory variable for ELT-LV. The model quality data were excellent with model fit SRMR $=0.045$, composite reliability values $>0.8$, Cronbach alpha values $>0.8$, AVE $>0.5$ and rho_A values $>0.8$. We found that $54.7 \%$ of the variance in the outcome LV was explained by significant effects of AOPP/ MDA LV, episodes LV, ELT-LV, TUD and female sex. 22.0\% of the variance in AOPP/MDA LV was explained by HDL/ CMPAase LV, sex and BMI, while $17.6 \%$ of the variance in
HDL/CMPAase LV was explained by episodes LV, TUD and BMI. $27.2 \%$ of the variance in hsCRP was explained by BMI and sex. There were total effects of ELT-LV on hsCRP $(\mathrm{t}=$ $2.51, \mathrm{p}=0.013)$, AOPP/MDA LV $(\mathrm{t}=2.27, \mathrm{p}=0.024)$ and HDL/ CMPAase LV $(\mathrm{t}=-3.39, \mathrm{p}=0.001)$. There were total indirect effects of ELT-LV on AOPP/MDA $(t=2.27, p=0.024)$. The effects of ELT-LV on HDL/CMPAase was mediated by BMI $(\mathrm{t}=-2.00, \mathrm{p}=0.015)$ and episodes LV $(\mathrm{t}=-2.43, \mathrm{p}=0.015)$, while the effects of ELT-LV on CRP were mediated by BMI $(\mathrm{t}=2.51, \mathrm{p}=0.013)$.

\section{Effects of ELT-LV on VFT}

Figure 3 examines the effects of ELT-LV on VFT considering that severity of illness and staging could affect VFT. There were no significant effects of any of the biomarkers on VFT and therefore these indicators were eliminated from 


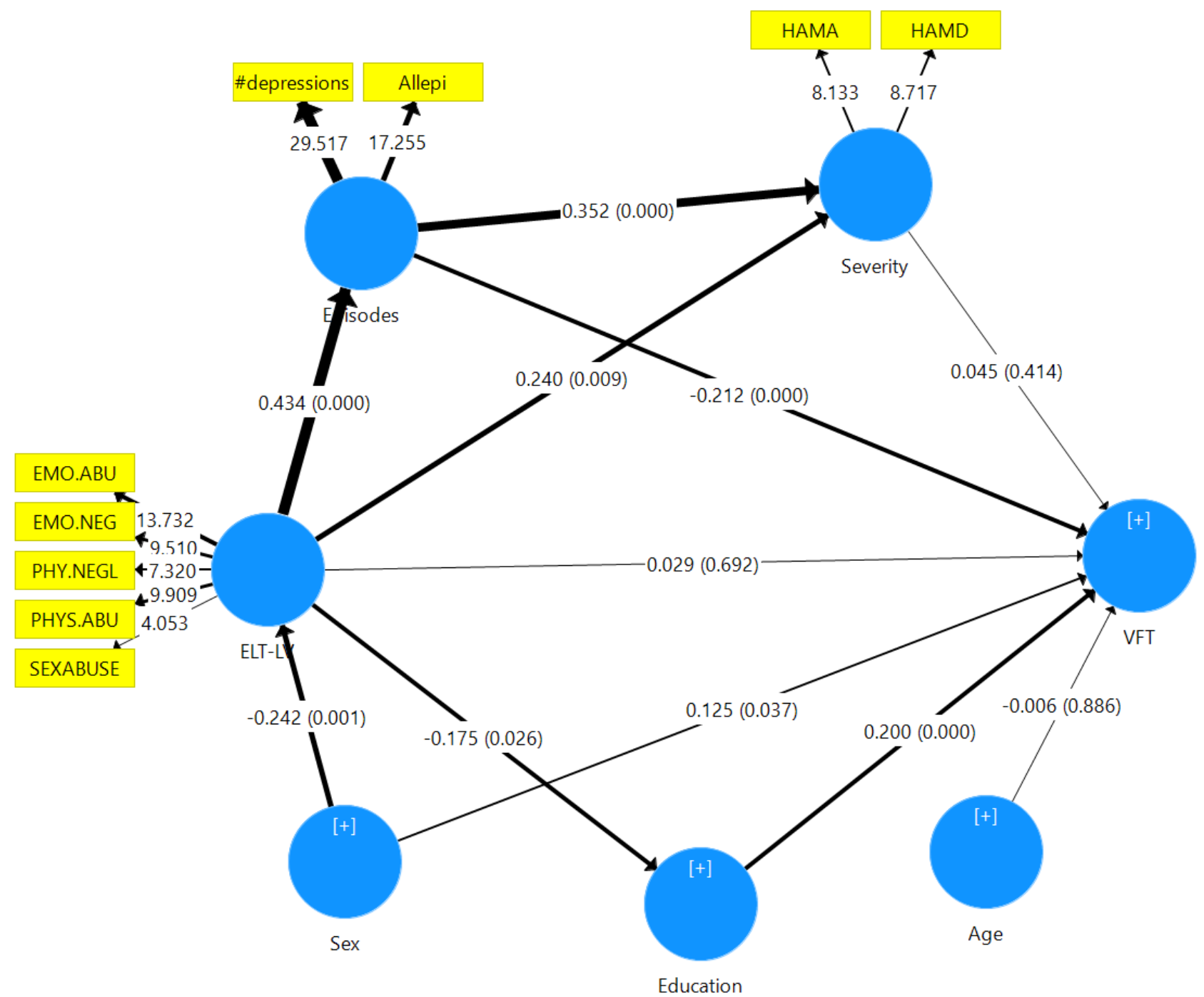

Figure 3: Results of partial least squares (PLS) path analysis with verbal fluency test (VFT) as outcome variable and a latent vector (LV) extracted from Hamilton Depression (HAM-D) and Anxiety (HAM-A) Rating Scale scores; episodes LV, extracted from number of depressions and total number of episodes; age; education; sex and a LV extracted from 5 early lifetime trauma (ELT LV) as explanatory variables.

the model. Figure 3 shows a PLS model with VFT as final outcome and severity LV, episodes LV, education and ELTLV as input variables while adjusting for age and sex. The model quality data were again excellent with SRMR $=0.058$, and Cronbach alpha values > 0.843, rho_A > 0.881 , composite reliabilities $>0.856$ and AVE $>0.553$. We found that $20.0 \%$ of the variance in VFT was explained by episodes LV, education and sex, while severity LV was not significant. There were specific indirect effects of ELTLV on VFT, which were mediated by episodes LV $(t=-2.55$, $\mathrm{p}=0.010)$.

\section{Discussion}

\section{ELT strongly predicts affective phenomenology}

The first major finding of this study is that increased ELTLV scores are highly significantly associated with mood disorders, in particular with $\mathrm{BD}$, and many characteristics of affective phenomenology, including severity of depression and anxiety, staging characteristics including number of mood episodes, suicidal behaviours including number of lifetime suicide attempts and current suicidal ideation, the presence of comorbid anxiety disorders and type of treatments received namely use of mood stabilizers, lithium and antipsychotics. Cross-sectional 
and longitudinal studies show that ELT and especially multiple ELTs or the accumulation of different traumatic events in childhood are associated with the development of depression later in life [83-85]. A recent review shows that childhood ELTs and especially multiple ELTs also increase risk for developing $\mathrm{BD}$ and more severe phenotypes of BD [64,86-88]. Our findings also extent those of previous papers showing that ELT may be associated with increased severity of illness and more suicidal behaviours [55,56], recurrent episodes [89], and comorbid anxiety disorders $[57,58,90]$. In addition, we found that ELT-LV has a strong impact on lowered income, increased disabilities and a lowered HR-QoL. A prospective study showed that there were only weak connections between ELT and lowered QoL in later life [91], while in BD patients, ELT is accompanied by lowered HR-QoL [92]. Moreover, we found that ELT-LV also affected BMI, but not smoking behaviour. Previously, it was reported that among individuals with psychopathology, ELT may predispose to adult cigarette smoking [93]. Previous research also showed a connection between ELT and increased metabolic burden. For example, in first-episode psychosis patients, those with ELT had higher BMI when compared with healthy controls [94], while ELT is also associated with obesity [95].

\section{The effects of ELT on affective phenomenology are mediated by staging and lowered antioxidant defences}

The second major finding of this study is that the effects of the vulnerability factor ELT-LV on affective phenomenology are in part mediated by recurrent episodes and lipidassociated antioxidant defences, namely lowered HDLcholesterol and CMPAase activity. In addition, there was a significant association between recurrent episodes and lowered levels of these lipid-associated antioxidants so that a latent vector could be computed reflecting the combined effects of episode recurrence (EPI) and these biomarkers (BIOL), named EPIBIOL-LV. This LV reflects the shared variance between increased staging and lowered antioxidant defences in affective disorders. While both types of variables have significant effects on affective phenomenology their combination showed stronger effects.

Previously, we have reported that there is a strong association between recurrence of depressive and (hypo) manic episodes and lowered CMPAase activity, indicating that sensitization mechanisms are involved in lowered levels of these antioxidants [29]. In another study, we found that sexual abuse was significantly associated with lowered antioxidant defences, including zinc, albumin and SH-groups [65]. Given the cross-sectional nature of our study, it is difficult to conclude whether lowered antioxidant defences are a primary phenomenon or occur as a consequence of staging. Nevertheless, patients with drug-naïve first-episode psychosis (of whom part develop BD) show lowered PON1 activity levels, indicating that lowered PON1 activity is already present during a first episode [96]. Thus, the most parsimonious explanation is that staging, lowered antioxidant defences and shared variance among staging and lowered antioxidant defences contribute to affective phenomenology.

We have discussed previously that lowered levels of PON1 or CMPAase activity and lowered HDL-cholesterol levels are tightly coupled phenomena in mood disorders [97]. Thus, PON1 is integrated into HDL molecules and protects HDL, low-density lipoprotein and lipids against oxidation. Mood disorders are accompanied by immuneinflammatory responses including activated macrophages that produce nitric oxide (NO) and myeloperoxidase (MPO), thereby generating $\mathrm{HCl}$ and peroxynitrite, which in turn may attenuate PON1 binding to HDL and damage and inactivate PON1 in HDL [98]. This downregulation of the PON1/CMPAase - HDL functional complex is accompanied by increased MPO activity and thus increased production of $\mathrm{HCl}$ and peroxynitrite which may generate more lipid and protein oxidation as measured with MDA and AOPP [97,98].

Previously, we have reported that in mood disorders and first episode psychosis, lowered PON1-associated antioxidant defences are associated with signs of increased oxidation and immune activation as indicated by increased levels of interleukin (IL)-6, IL-4 and IL-10 $[19,29,96,97]$. Here, we found that lowered HDL-PON1 antioxidant defences are associated with increased lipid and protein oxidation and consequently with severity of illness and that increased AOPP levels additionally predict CGI and lowered HR-QoL. Interestingly, in the current study we found that the significant effects of ELT-LV on hsCRP levels were completely mediated by BMI. These data extend those of previous reports that plasma hsCRP is strongly determined by BMI [66]. A previous study reported a quadratic association between depression and BMI categories with significant associations between depression and underweighted or overweighted individuals [99]. Nevertheless, here we found a linear association between BMI and hsCRP. Most importantly, while lowered antioxidant defences and increased oxidative stress biomarkers affected the outcome of affective disorders, hsCRP did not have any effect. 
All in all, this study established two new paths: (a) from the vulnerability factor ELT-LV $\rightarrow$ a combined staging-biomarker $\rightarrow$ increased lipid/protein oxidation $\rightarrow$ further aggravation of the affective phenotype; and (b) from the vulnerability factor ELT-LV $\rightarrow$ increased BMI $\rightarrow$ increased hsCRP. Therefore, we may conclude that while lipid-associated antioxidant defences and lipid/protein oxidation play a role in the outcome of affective disorders, hsCRP is not involved, although it may be increased as a consequence of increased BMI that may occur in affective disorders.

\section{Effects of female sex on affective phenomenology}

The third major finding of this study is that female sex was associated with an increased incidence of affective disorders, affective phenomenology and with higher ELT-LV scores. Firstly, we found that female sex increased severity of illness, suicidal ideation, suicide attempts, disabilities, use of psychotropic medications, and BMI and lowered WHO-QoL score and income. It is well known that females are twice as likely as males to develop mood and comorbid anxiety disorders and have higher scores on severity of illness and more affective symptoms [61-63]. These sex-differences are established across cultures even after controlling for help-seeking behaviors, suggesting biological differences $[100,101]$. Nevertheless, there is at least one exception, i.e. increased suicide rates in males than in females (not examined in the current study). The latter may be explained by increased use of violent means by males and seasonal effects [102,103].

Secondly, we found that the significant effects of sex on affective phenomenology are mediated by ELT-LV, suggesting that sex may drive affective phenomenology by modulating ELT. The results indicate that girls are more likely to suffer from childhood ELT and that this sex-interaction may explain the effects of sex on affective phenomenology. These results extend those of Etain et al. [104] who reported that affective phenomenology is modulated by a sex non-specific effect of ELT in that women with BD report more ELT than men, and women show stronger associations between ELT and BD characteristics, including number of depressive episodes and suicide attempts [104]. In this respect, it is interesting to note that girls being victimized by bullies at six years old are more likely than boys to remain a victim four years later [105]. Girls report more childhood physical abuse than boys, while ELT may have a more profound impact on girls than boys [106]. The latter authors reported that such effects may be related to sex differences in the insula's anterior circular sulcus. In our study, however, female sex appears to protect against lowered lipid-associated antioxidant defences and increased oxidation and therefore these neuro-oxidative pathways do not explain the effects of female sex on affective phenomenology. It is well known that HDL-cholesterol levels are significantly lower in males than in females, which in part explains attenuated antioxidant defences in men as compared with women [28]. How, female sex and its interactions with ELT and antioxidant defences (lower HDL-cholesterol in men) and nitro-oxidative stress (increased oxidative markers in men) modulate affective phenomenology will be examined in another study focusing on the combined effects of ELT and sex on oxidative stress.

\section{ELT-LV and deficits in semantic memory}

The fourth major finding of this study is that ELT-LV also predicts impairments in verbal fluency and that this effect is mediated by staging of illness. There is a vast literature that mood disorders are characterized by cognitive impairments including semantic memory $[16,107]$. There is now evidence that ELT predisposes towards cognitive dysfunctions including in the domains of memory, executive functioning and emotion regulation $[60,108]$.

\section{Conclusions}

A combination of five different ELTs appear to drive many aspects of affective phenomenology especially in women, indicating that children, especially girls, who experience ELT are at an increased risk to develop affective disorders with a more severe psychopathology. Moreover, the effects of ELT on affective phenomenology are in part mediated by staging and/or lowered lipid-associated antioxidant defences. The newly constructed latent vector, which reflects shared variance among staging and PON1 and HDL-associated antioxidant defences, is a second vulnerability factor that together with ELT is associated with affective phenomenology. The findings show that staging-associated antioxidant defences play an important role in affective disorders. Moreover, other lipidassociated antioxidants systems may play a role in affective disorders, including lowered levels of LCAT, vitamin E, coenzyme $Q_{10}$, glutathione and glutathione peroxidase. In addition, female sex appears to protect against lowered lipid-associated antioxidant defences. Therefore, ELT should be treated in the earliest phase of illness, whilst 
lipid-associated antioxidant defences are another target which could prevent further relapses. Recently, we have reviewed different strategies which may enhance PON1 activity, including administration of polyphenols, vitamin E/C and oleic acid, while also a Mediterranean diet and physical exercise and statins and fibrates may enhance PON1 activity [109]. Future research should (a) discover new treatments targeting PON1 binding to HDL to improve protection against activated neuro-oxidative and neuroimmune pathways and to remove consequent oxidative injuries from the body; and (b) examine the association between staging and antioxidant defences in prospective studies as well as the effects of ELT on these factors.

Funding: This study was supported by Health Sciences Postgraduate Program at Londrina State University, Parana, Brazil (UEL), and Ministry for Science and Technology of Brazil (CNPq). CNPq number 470344/20130 and CNPq number 465928/2014-5. MM is supported by a CNPq - PVE fellowship and the Health Sciences Graduate Program fellowship, State University of Londrina.

Acknowledgements: The authors wish to thank the Centre of Approach and Treatment for Smokers, Psychiatric Unit at UEL, Clinical Laboratory of the University Hospital and Laboratory of Research and Graduate College Hospital (LPG), Brazil.

Authorships: All authors contributed to the writing up of the paper. The work was designed by SOVN, MM, DSB, JBM and HOV. Data were collected by SOVN, HOV, AC, and JBM. Laboratory analyses were conducted by KLB, APM and DSB. Statistics were performed by MM. GM and BKP revised the manuscript and provided relevant intellectual content. All authors revised and approved the final draft.

\section{References}

1. Bolton JM, Gunnell D, Turecki G. Suicide risk assessment and intervention in people with mental illness. BMJ 2015;351:h4978.

2. Miret M, Ayuso-Mateos JL, Sanchez-Moreno J, Vieta E. Depressive disorders and suicide: Epidemiology, risk factors, and burden. Neurosci Biobehav Rev 2013;37:2372-2374.

3. Novick DM, Swartz HA, Frank E. Suicide attempts in bipolar I and bipolar II disorder: a review and meta-analysis of the evidence. Bipolar Disord 2010;12:1-9.

4. Birnbaum HG, Kessler RC, Kelley D, Ben-Hamadi R, Joish VN, Greenberg PE. Employer burden of mild, moderate, and severe major depressive disorder: mental health services utilization and costs, and work performance. Depress Anxiety 2010;27:7889.

5. Dean BB, Gerner D, Gerner RH. A systematic review evaluating health-related quality of life, work impairment, and healthcare costs and utilization in bipolar disorder. Curr Med Res Opin 2004;20:139-154.

6. Depp CA, Mausbach BT, Harmell AL, Savla GN, Bowie CR, Harvey PD, Patterson TL. Meta-analysis of the association between cognitive abilities and everyday functioning in bipolar disorder. Bipolar Disord 2012;14:217-226.

7. GBD 2015 DALYs and HALE Collaborators. Global, regional, and national disability-adjusted life-years (DALYs) for 315 diseases and injuries and healthy life expectancy (HALE), 1990-2015: a systematic analysis for the Global Burden of Disease Study 2015. Lancet 2016;388: 1603-1658.

8. Arias-de la Torre J, Vilagut G, Martín V, Molina AJ, Alonso J. Prevalence of major depressive disorder and association with personal and socio-economic factors. Results for Spain of the European Health Interview Survey 2014-2015. J Affect Disord. 2018;239:203-207.

9. Zhou Q, Fan L, Yin Z. Association between family socioeconomic status and depressive symptoms among Chinese adolescents: Evidence from a national household survey. Psychiatry Res. 2018;259:81-88.

10. MacPherson HA, Weinstein SM, West AE. Non-Suicidal SelfInjury in Pediatric Bipolar Disorder: Clinical Correlates and Impact on Psychosocial Treatment Outcomes. J Abnorm Child Psychol. 2018;46(4):857-870.

11. Joinson C, Kounali D, Lewis G. Family socioeconomic position in early life and onset of depressive symptoms and depression: a prospective cohort study. Soc Psychiatry Psychiatr Epidemiol. 2017;52(1):95-103.

12. Nunes SO, Vargas HO, Prado E, Barbosa DS, de Melo LP, Moylan S, Dodd S, Berk M. The shared role of oxidative stress and inflammation in major depressive disorder and nicotine dependence. Neurosci Biobehav Rev. 2013;37(8):1336-1345.

13. Mathew AR, Hogarth L, Leventhal AM, Cook JW, Hitsman B. Cigarette smoking and depression comorbidity: systematic review and proposed theoretical model. Addiction. 2017;112(3):401-412.

14. Weinberger AH, Seng EK, Esan H, Shuter J. Perceived risks and benefits of quitting smoking in a sample of adults living with HIV/AIDS. AIDS Care. 2018;30(5):564-568.

15. de Melo LGP, Nunes SOV, Anderson G, Vargas HO, Barbosa DS, Galecki P, Carvalho AF, Maes M. Shared metabolic and immune-inflammatory, oxidative and nitrosative stress pathways in the metabolic syndrome and mood disorders. Prog Neuropsychopharmacol Biol Psychiatry. 2017;78:34-50.

16. Brunet J, Hudon C, Macoir J, Belleville S, Rousseau F, Bouchard RW, Verret L, Chertkow H, Chayer C, Kergoat MJ, Joubert S. The relation between depressive symptoms and semantic memory in amnestic mild cognitive impairment and in late-life depression. J Int Neuropsychol Soc. 2011;17(5):865-874.

17. Maes M. A review on the acute phase response in major depression. Rev Neurosci 1993;4(4):407-16. Review.

18. Maes M, Galecki P, Chang YS, Berk M. A review on the oxidative and nitrosative stress (O\&NS) pathways in major depression and their possible contribution to the (neuro)degenerative processes in that illness. Prog Neuropsychopharmacol Biol Psychiatry 2011;35:676-692. 
19. Maes M, Landucci Bonifacio K, Morelli NR, Vargas HO, Barbosa DS, Carvalho AF, Nunes SOV. Major Differences in Neurooxidative and Neuronitrosative Stress Pathways Between Major Depressive Disorder and Types I and II Bipolar Disorder. Mol Neurobiol. 2018 Apr 21. doi: 10.1007/s12035-018-1051-7. [Epub ahead of print] PubMed PMID: 29681025.

20. Moylan S, Berk M, Dean OM, Samuni Y, Williams LJ, O’Neil A, Hayley AC, Pasco JA, Anderson G, Jacka FN, Maes M. Oxidative \& nitrosative stress in depression: why so much stress? Neurosci Biobehav Rev. 2014;45:46-62.

21. Maes M, Delanghe J, Meltzer HY, Scharpé S, D’Hondt P, Cosyns P. Lower degree of esterification of serum cholesterol in depression: relevance for depression and suicide research. Acta Psychiatr Scand 1994;90(4):252-258.

22. Maes M, Smith R, Christophe A, Vandoolaeghe E, Van Gastel A, Neels H, Demedts P, Wauters A, Meltzer HY. Lower serum highdensity lipoprotein cholesterol (HDL-C) in major depression and in depressed men with serious suicidal attempts: relationship with immune-inflammatory markers. Acta Psychiatr Scand 1997;95(3):212-221.

23. Maes M, De Vos N, Pioli R, Demedts P, Wauters A, Neels H, Christophe A. Lower serum vitamin E concentrations in major depression. Another marker of lowered antioxidant defences in that illness. J Affect Disord 2000;58(3):241-246.

24. Maes M, Mihaylova I, Kubera M, Uytterhoeven M, Vrydags $\mathrm{N}$, Bosmans E. Lower plasma Coenzyme Q10 in depression: a marker for treatment resistance and chronic fatigue in depression and a risk factor to cardiovascular disorder in that illness. Neuro Endocrinol Lett 2009;30(4):462-469.

25. Sobczak S, Honig A, Christophe A, Maes M, Helsdingen RW, De Vriese SA, Riedel WJ. Lower high-density lipoprotein cholesterol and increased omega- 6 polyunsaturated fatty acids in first-degree relatives of bipolar patients. Psychol Med. 2004;34(1):103-112.

26. Tsuboi H, Tatsumi A, Yamamoto K, Kobayashi F, Shimoi K, Kinae N. Possible connections among job stress, depressive symptoms, lipid modulation and antioxidants. J Affect Disord. 2006;91(1):63-70.

27. Bortolasci CC, Vargas HO, Souza-Nogueira A, Barbosa DS, Moreira EG, Nunes SO, Berk M, Dodd S, Maes M. Lowered plasma paraoxonase (PON)1 activity is a trait marker of major depression and PON1 Q192R gene polymorphism-smoking interactions differentially predict the odds of major depression and bipolar disorder. J Affect Disord 2014;159:23-30.

28. Nunes SO, Piccoli de Melo LG, Pizzo de Castro MR, Barbosa DS, Vargas HO, Berk M, Maes M. Atherogenic index of plasma and atherogenic coefficient are increased in major depression and bipolar disorder, especially when comorbid with tobacco use disorder. J Affect Disord 2015;172:55-62.

29. Moreira EG, Correia DG, Bonifácio KL, Moraes JB, Cavicchioli FL, Nunes CS, Nunes SOV, Vargas HO, Barbosa DS, Maes M. Lowered PON1 activities are strongly associated with depression and bipolar disorder, recurrence of (hypo)mania and depression, increased disability and lowered quality of life. World J Biol Psychiatry 2017;30:1-13.

30. Liu T, Zhong S, Liao X, Chen J, He T, Lai S, Jia Y. A MetaAnalysis of Oxidative Stress Markers in Depression. PLoS One 2015;10(10):e0138904.
31. Peet M, Murphy B, Shay J, Horrobin D. Depletion of omega-3 fatty acid levels in red blood cell membranes of depressive patients. Biol Psychiatry 1998; 43(5):315-319.

32. Maes M, Smith R, Christophe A, Cosyns P, Desnyder R, Meltzer $H$. Fatty acid composition in major depression: decreased omega 3 fractions in cholesteryl esters and increased C20: 4 omega 6/C20:5 omega 3 ratio in cholesteryl esters and phospholipids. J Affect Disord 1996;38(1):35-46.

33. Maes M, Christophe A, Delanghe J, Altamura C, Neels H, Meltzer HY. Lowered omega3 polyunsaturated fatty acids in serum phospholipids and cholesteryl esters of depressed patients. Psychiatry Res 1999;85(3):275-291.

34. Gomes C, Martinho FC, Barbosa DS, Antunes LS, Póvoa HCC, Baltus THL, Morelli NR, Vargas HO, Nunes SOV, Anderson G, Maes M. Increased Root Canal Endotoxin Levels are Associated with Chronic Apical Periodontitis, Increased Oxidative and Nitrosative Stress, Major Depression, Severity of Depression, and a Lowered Quality of Life. Mol Neurobiol 2017; Apr 28. doi: 10.1007/s12035-017-0545-z. [Epub ahead of print] PubMed PMID: 28455694.

35. Roomruangwong C, Barbosa DS, Matsumoto AK, Nogueira AS, Kanchanatawan B, Sirivichayakul S, Carvalho AF, Duleu S, Geffard M, Moreira EG, Maes M. Activated neuro-oxidative and neuro-nitrosative pathways at the end of term are associated with inflammation and physio-somatic and depression symptoms, while predicting outcome characteristics in mother and baby. J Affect Disord 2017;223:49-58.

36. Bilici M, Efe H, Köroğlu MA, Uydu HA, Bekaroğlu M, Değer O. Antioxidative enzyme activities and lipid peroxidation in major depression: alterations by antidepressant treatments. J Affect Disord 2001;64(1):43-51.

37. Khanzode SD, Dakhale GN, Khanzode SS, Saoji A, Palasodkar R. Oxidative damage and major depression: the potential antioxidant action of selective serotonin re-uptake inhibitors. Redox Rep 2003;8(6):365-370.

38. Ozcan ME, Gulec M, Ozerol E, Polat R, Akyol O. Antioxidant enzyme activities and oxidative stress in affective disorders. Int Clin Psychopharmacol 2004;19(2):89-95.

39. Andreazza AC, Kauer-Sant'anna M, Frey BN, Bond DJ, Kapczinski F, Young LT, Yatham LN. Oxidative stress markers in bipolar disorder: a meta-analysis. J Affect Disord 2008;111(23):135-144.

40. Maes M, Mihaylova I, Leunis JC. Increased serum IgM antibodies directed against phosphatidyl inositol (Pi) in chronic fatigue syndrome (CFS) and major depression: evidence that an IgM-mediated immune response against $\mathrm{Pi}$ is one factor underpinning the comorbidity between both CFS and depression. Neuro Endocrinol Lett 2007;28(6):861-867.

41. Maes M, Mihaylova I, Kubera M, Leunis JC, Geffard M. IgMmediated autoimmune responses directed against multiple neoepitopes in depression: new pathways that underpin the inflammatory and neuroprogressive pathophysiology. J Affect Disord 2011;135(1-3):414-418.

42. Sluzewska A, Rybakowski J, Bosmans E, Sobieska M, Berghmans R, Maes M, Wiktorowicz K. Indicators of immune activation in major depression. Psychiatry Res. 1996;64(3):161167.

43. Maes M, Kubera M, Leunis JC. The gut-brain barrier in major depression: intestinal mucosal dysfunction with an increased translocation of LPS from gram negative enterobacteria (leaky 
gut) plays a role in the inflammatory pathophysiology of depression. Neuro Endocrinol Lett. 2008;29(1):117-124.

44. Maes M, Christophe A, Bosmans E, Lin A, Neels H. In humans, serum polyunsaturated fatty acid levels predict the response of proinflammatory cytokines to psychologic stress. Biol Psychiatry. 2000;47(10):910-920.

45. Marangoni C, Hernandez M, Faedda GL. The role of environmental exposures as risk factors for bipolar disorder: A systematic review of longitudinal studies. J Affect Disord 2016;193:165-74.

46. Catone G, Marwaha S, Kuipers E, Lennox B, Freeman D, Bebbington $\mathrm{P}$, Broome M. Bullying victimisation and risk of psychotic phenomena: analyses of British national survey data. Lancet Psychiatry 2015;2:618-624.

47. Fisher HL, Jones PB, Fearon P, Craig TK, Dazzan P, Morgan K, Hutchinson G, Doody GA, McGuffin P, Leff J, Murray RM, Morgan $C$. The varying impact of type, timing and frequency of exposure to childhood adversity on its association with adult psychotic disorder. Psychol Med 2010;40:1967-1978.

48. Takizawa R, Maughan B, Arseneault L. Adult health outcomes of childhood bullying victimization: evidence from a five-decade longitudinal British birth cohort. Am J Psychiatry 2014;171:777784.

49. Alvarez MJ, Roura P, Oses A, Foguet Q, Sola J, Arrufat FX. Prevalence and clinical impact of childhood trauma in patients with severe mental disorders. J Nerv Ment Dis 2011;199:156161.

50. Bergink V, Larsen JT, Hillegers MH, Dahl SK, Stevens H, Mortensen PB, Petersen L, Munk-Olsen T. Childhood adverse life events and parental psychopathology as risk factors for bipolar disorder. Transl Psychiatry 2016;6:e929.

51. Heim C, Shugart M, Craighead WE, Nemeroff CB. Neurobiological and psychiatric consequences of child abuse and neglect. Dev Psychobiol 2010;52:671-690.

52. Larsson S, Andreassen OA, Aas M, et al. High prevalence of childhood trauma in patients with schizophrenia spectrum and affective disorder. Compr Psychiatry 2013;54(2):123-127.

53. Agnew-Blais J, Danese A. Childhood maltreatment and unfavourable clinical outcomes in bipolar disorder: a systematic review and meta-analysis. Lancet Psychiatry 2016;3(4):342-349.

54. Jansen K, Cardoso TA, Fries GR, Branco JC, Silva RA, KauerSant’Anna M, Kapczinski F, Magalhaes PV. Childhood trauma, family history, and their association with mood disorders in early adulthood. Acta Psychiatr Scand 2016;134:281-286.

55. Krug EG, Dahlberg LL, Mercy J, Zwi A, Lozano R. Child abuse and neglect by parents and other caregivers. World Health Organization. World Report on Violence and Health, 2002;pp. 59-86.

56. Schoedl AF, Costa MC, Mari JJ, Mello MF, Tyrka AR, Carpenter LL, Price LH. The clinical correlates of reported childhood sexual abuse: an association between age at trauma onset and severity of depression and PTSD in adults. J Child Sex Abus 2010;19:156-170.

57. Maniglio, R. Prevalence of child sexual abuse among adults and youths with bipolar disorder: a systematic review. Clin Psychol Rev 2013;33(4):561-573.

58. Leboyer M, Etain B, Mathieu F, Henry C, Jamain S,Bellivier F. Childhood affective trauma in bipolar affective disorder. Bipolar Disord 2007;9(Suppl. 1):9-10.
59. Danese A, Tan M. Childhood maltreatment and obesity: systematic review and meta-analysis. Mol Psychiatry 2014;19(5):544-554.

60. Pechtel P, Pizzagalli DA. Effects of early life stress on cognitive and affective function: an integrated review of human literature. Psychopharmacology (Berl). 2011;214(1):55-70.

61. Kornstein SG, Schatzberg AF, Thase ME, Yonkers KA, McCullough JP, Keitner GI, Gelenberg AJ, Ryan CE, Hess AL, Harrison W, Davis SM, Keller MB. Gender differences in chronic major and double depression. J Affect Disord. 2000;60(1):1-11.

62. Angst J, Dobler-Mikola A. Do the diagnostic criteria determine the sex ratio in depression? J Affect Disord. 1984;7(3-4):189198.

63. Frank SA, Swingland IR. Sex ratio under conditional sex expression. J Theor Biol. 1988;135(3):415-418.

64. Etain B, Lajnef M, Henry C, Aubin V, Azorin JM, Bellivier F, Bougerol T, Courtet P, Gard S, Kahn JP, Passerieux C, Leboyer M; FACE-BD Clinical Coordinating Center (FondaMental Foundation); FACE-BD Data Coordinating Center (FondaMental Foundation); FACE-BD Clinical Sites and Principal Collaborators in France. Childhood trauma, dimensions of psychopathology and the clinical expression of bipolar disorders: A pathway analysis. J Psychiatr Res. 2017;95:37-45.

65. Moraes JB, Maes M, Roomruangwong C, Bonifacio KL, Barbosa DS, Vargas HO, Anderson G, Kubera M, Carvalho AF, Nunes SOV. In major affective disorders, early life trauma predict increased nitro-oxidative stress, lipid peroxidation and protein oxidation and recurrence of major affective disorders, suicidal behaviors and a lowered quality of life. Metab Brain Dis. 2018;33(4):1081-1096.

66. Moraes JB, Maes M, Barbosa DS, Ferrari TZ, Uehara MKS, Carvalho AF, Nunes SOV. Elevated C-reactive Protein Levels in Women with Bipolar Disorder may be Explained by a History of Childhood Trauma, Especially Sexual Abuse, Body Mass Index and Age. CNS Neurol Disord Drug Targets. 2017;16(4):514-521.

67. Bernstein DP, Stein JA, Newcomb MD, Walker E, Pogge D, Ahluvalia T, Stokes J, Handelsman L, Medrano M, Desmond D, Zule W. Development and validation of a brief screening version of the Childhood Trauma Questionnaire. Child Abuse Negl. 2003;27(2):169-190.

68. Grassi-Oliveira R, Stein LM, Pezzi JC. Translation and content validation of the Childhood Trauma Questionnaire into Portuguese language. Rev Saude Publica 2006;40:249-255.

69. Del-Ben CM, Vilela JAA, Crippa JAdS, Hallak JEC, Labate CM, Zuardi AW. Confiabilidade da "Entrevista Cl?nica Estruturada para o DSM-IV - Versao Clinica traduzida para o portugues. Rev Bras Psiquiatr 2001;23:156-159.

70. HAMILTON M. A rating scale for depression. J Neurol Neurosurg Psychiatry. 1960;23:56-62.

71. Moreno RA, Moreno DH. Escalas de depressao de Montgomery \& Asberg (MADRS) e de Hamilton (HAM-D) / Hamilton and Montgomery \& Asberg depression rating scales. Rev Psiquiatr Clin 1998;25:262-272.

72. HAMILTON M. The assessment of anxiety states by rating. $\mathrm{Br}$ J Med Psychol. 1959;32(1):50-55.

73. Posner K, Brown GK, Stanley B, Brent DA, Yershova KV, Oquendo MA, Currier GW, Melvin GA, Greenhill L, Shen S, Mann JJ. The Columbia-Suicide Severity Rating Scale: initial validity and internal consistency findings from three multisite 
studies with adolescents and adults. Am J Psychiatry. 2011;168(12):1266-1277.

74. Posner K, Brent D, Lucas C, Gould M, Stanley B, Brown G, Fisher P, Zelazny J, Burke A, Oquendo M, Mann J. ESCALA DE AVALIAÇÃO DO RISCO DE SUICÍDIO DE COLUMBIA (C-SSRS), Base de partida/Versão de triage, Versão de 14/01/2009, The Research Foundation for Mental Hygiene, Inc, 2009.

75. Guy W, editor. ECDEU Assessment Manual for Psychopharmacology. Rockville, MD: US Department of Health, Education, and Welfare Public Health Service Alcohol, Drug Abuse, and Mental Health Administration; 1976.

76. Sheehan DV, Harnett-Sheehan K, Raj BA. The measurement of disability. Int Clin Psychopharmacol. 1996;11 Suppl 3:89-95.

77. Skevington SM, Lotfy M, O'Connell KA; WHOQOL Group. The World Health Organization's WHOQOL-BREF quality of life assessment: psychometric properties and results of the international field trial. A report from the WHOQOL group. Qual Life Res. 2004;13(2):299-310.

78. Fleck MP, Louzada S, Xavier M, Chachamovich E, Vieira G, Santos L, Pinzon V. [Application of the Portuguese version of the abbreviated instrument of quality life WHOQOL-bref]. Rev Saude Publica. 2000;34(2):178-183.

79. Bastos AS, Loureiro AP, de Oliveira TF, Corbi SC, Caminaga RM, Junior CR, Orrico SR (2012) Quantitation of malondialdehyde in gingival crevicular fluid by a high-performance liquid chromatography-based method. Anal Biochem 423:141-146.

80. Hanasand M, Omdal R, Norheim KB, Gransson LG, Brede C, Jonsson $\mathrm{G}$. Improved detection of advanced oxidation protein products in plasma. Clin Chim Acta 2012;413:901-906.

81. Ringle CM, Wende S, Becker J-M. SmartPLS 3. Bönningstedt: SmartPLS, 2015. Retrieved from http://www.smartpls.com

82. Hu L, Bentler PM. Cutoff criteria for fit indexes in covariance structure analysis: Conventional criteria versus new alternatives. Structural Equation Modeling: A Multidisciplinary Journal. 1999;6:1-55, DOI: 10.1080/10705519909540118

83. Widom CS, DuMont K, Czaja SJ. A prospective investigation of major depressive disorder and comorbidity in abused and neglected children grown up. Arch Gen Psychiatry. 2007;64(1):49-56.

84. Tanskanen A, Hintikka J, Honkalampi K, Haatainen K, Koivumaa-Honkanen $\mathrm{H}$, Viinamäki H. Impact of multiple traumatic experiences on the persistence of depressive symptoms--a population-based study. Nord J Psychiatry. 2004;58(6):459-464.

85. Negele A, Kaufhold J, Kallenbach L, Leuzinger-Bohleber M. Childhood Trauma and Its Relation to Chronic Depression in Adulthood. Depress Res Treat. 2015;2015:650804.

86. Aas M, Henry C, Bellivier F, Lajnef M, Gard S, Kahn JP, Lagerberg TV, Aminoff SR, Bjella T, Leboyer M, Andreassen OA, Melle I, Etain B. Affective lability mediates the association between childhood trauma and suicide attempts, mixed episodes and co-morbid anxiety disorders in bipolar disorders. Psychol Med. 2017;47(5):902-912.

87. Alvarez MJ, Roura P, Osés A, Foguet Q, Sol $\rightarrow$ J, Arrufat FX. Prevalence and clinical impact of childhood trauma in patients with severe mental disorders. J Nerv Ment Dis. 2011;199(3):156161.

88. Janiri D, Sani G, Danese E, Simonetti A, Ambrosi E, Angeletti G, Erbuto D, Caltagirone C, Girardi P, Spalletta G. Childhood traumatic experiences of patients with bipolar disorder type I and type II. J Affect Disord. 2015;175:92-97.

89. Agnew-Blais J, Danese A. Childhood maltreatment and unfavourable clinical outcomes in bipolar disorder: a systematic review and meta-analysis. Lancet Psychiatry. 2016;3(4):342-349.

90. Garno JL, Goldberg JF, Ramirez PM, Ritzler BA. Impact of childhood abuse on the clinical course of bipolar disorder. $\mathrm{Br}$ J Psychiatry 2005;186:121-125.

91. Ventegodt S, Flensborg-Madsen T, Andersen NJ, Merrick J. Which factors determine our quality of life, health and ability? Results from a Danish population sample and the Copenhagen perinatal cohort. J Coll Physicians Surg Pak. 2008;18(7):445450.

92. Erten E, Funda Uney A, Saatçioğlu Ö, Özdemir A, Fıstıkçı N, Çakmak D. Effects of childhood trauma and clinical features on determining quality of life in patients with bipolar I disorder. J Affect Disord. 2014;162:107-113.

93. Spratt EG, Back SE, Yeatts SD, Simpson AN, McRae-Clark A, Moran-Santa Maria MM, Price KL, Hartwell KT, Brady KT. Relationship between child abuse and adult smoking. Int J Psychiatry Med. 2009;39(4):417-426.

94. Hepgul N, Pariante CM, Dipasquale S, DiForti M, Taylor H, Marques TR, Morgan C, Dazzan P, Murray RM, Mondelli V. Childhood maltreatment is associated with increased body mass index and increased C-reactive protein levels in firstepisode psychosis patients. Psychol Med. 2012;42(9):18931901.

95. Danese A, Tan M. Childhood maltreatment and obesity: systematic review and meta-analysis. Mol Psychiatry. 2014;19(5):544-554.

96. Brinholi FF, Noto C, Maes M, Bonifácio KL, Brietzke E, Ota VK, Gadelha A, Cordeiro Q, Belangero SI, Bressan RA, Vargas HO, Higachi L, de Farias CC, Moreira EG, Barbosa DS. Lowered paraoxonase 1 (PON1) activity is associated with increased cytokine levels in drug naïve first episode psychosis. Schizophr Res. 2015;166(1-3):225-230.

97. Maes M, Bonifacio KL, Morelli NR, Vargas HO, Moreira EG, St Stoyanov D, Barbosa DS, Carvalho AF, Nunes SOV. Generalized Anxiety Disorder (GAD) and Comorbid Major Depression with GAD Are Characterized by Enhanced Nitro-oxidative Stress, Increased Lipid Peroxidation, and Lowered Lipid-Associated Antioxidant Defenses. Neurotox Res. 2018 May 7. doi: 10.1007/ s12640-018-9906-2. [Epub ahead of print] PubMed PMID: 29736827.

98. Gugliucci A, Menini T. Paraoxonase 1 and HDL maturation. Clin Chim Acta. 2015;439:5-13.

99. de Wit LM, van Straten A, van Herten M, Penninx BW, Cuijpers $P$. Depression and body mass index, a u-shaped association. BMC Public Health. 2009;9:14.

100. Seney ML, Sibille E. Sex differences in mood disorders: perspectives from humans and rodent models. Biol Sex Differ. 2014;5(1):17.

101. Weissman MM, Klerman GL. Sex differences and the epidemiology of depression. Arch Gen Psychiatry. 1977;34(1):98-111.

102. Vörös V, Osváth P, Fekete S. Gender differences in suicidal behavior. Neuropsychopharmacol Hung. 2004;6(2):65-71. 
103. Maes M, Cosyns P, Meltzer HY, De Meyer F, Peeters D. Seasonality in violent suicide but not in nonviolent suicide or homicide. Am J Psychiatry.1993;150(9):1380-1385.

104. Etain B, Mathieu F, Liquet S, Raust A, Cochet B, Richard JR, Gard S, Zanouy L, Kahn JP, Cohen RF, Bougerol T, Henry C, Leboyer M, Bellivier F. Clinical features associated with traitimpulsiveness in euthymic bipolar disorder patients. J Affect Disord. 2013;144:240-247.

105. Wolke D, Woods S, Samara M. Who escapes or remains a victim of bullying in primary school? Br J Dev Psychol. 2009;27(Pt 4):835-851.

106. Klabunde M, Weems CF, Raman M, Carrion VG. The moderating effects of sex on insula subdivision structure in youth with posttraumatic stress symptoms. Depress Anxiety. 2017;34(1):51-58.
107. Lehrner J, Coutinho G, Mattos P, Moser D, Pflüger M, Gleiss A, Auff E, Dal-Bianco P, Pusswald G, Stögmann E. Semantic memory and depressive symptoms in patients with subjective cognitive decline, mild cognitive impairment, and Alzheimer's disease. Int Psychogeriatr. 2017;29(7):1123-1135.

108. Kaplan GA, Turrell G, Lynch JW, Everson SA, Helkala EL, Salonen JT. Childhood socioeconomic position and cognitive function in adulthood. Int J Epidemiol. 2001;30(2):256-63.

109. Moreira EG, Boll KM, Correia DG, Soares JF, Rigobello C, Maes M. Why should neuroscientisns and psychiatrists worry about Paraoxonase 1? Submitted, 2018. 